McElroy, T., \& Seta, J. J. (2006). Does it matter if it involves my group? How the importance of collective-esteem influences a group-based framing task. Social Cognition, 24(4): 496-510. Published by Guilford Press (ISSN: 0278016X). Copyright Guilford Press. Reprinted with permission of The Guilford Press.

\title{
Does It Matter If It Involves My Group? How the Importance of Collective-Esteem Influences a Group- Based Framing Task
}

Todd McElroy and John J. Seta

\author{
ABSTRACT \\ Studies that have addressed questions concerning when framing effects are \\ likely to occur have produced mixed results. In this article we examine \\ how differences in personality factors influence a group-based framing \\ task. Specifically, when high collective importance individuals evaluated \\ a framing task involving their group no framing effects were observed. Different \\ results were obtained for low collective individuals. When low collective \\ individuals evaluated a task involving their group, the typical \\ framing effects were found. These results are interpreted in light of the dual \\ analytic-holistic analysis.
}


Most people agree that preference for one option over another should remain constant regardless of whether the options are presented positively, in terms of gains, or negatively, in terms of losses. Yet, as a large body of research demonstrates, people do tend to change their preferences based on how the alternatives are presented. This change, or preference reversal, has become known as framing.

The framing phenomenon, as derived from prospect theory (Kahneman \&Tversky, 1979), has become the most widely tested example of irrational decision-making. For over two decades investigations in numerous research domains have tested and applied this phenomenon-proof of its viability and its ability to stimulate interest. Most of the framing tasks investigated follow the standard risky-choice format similar to the Asian disease problem (see Appendix 1). However, not all research has been supportive and the framing effect seems to be plagued with a number of inconsistencies (see Kuhberger, 1998 and Levin, Schneider \& Gaeth, 1998 for reviews).

For example, Fagley and Miller (1990) investigated how personal factors of risk-taking predisposition and sex would affect the strength of framing. Their overall findings suggested a weaker framing effect for males and an unclear relationship for risk-taking predisposition which seemed to be obscured by the situation or "arena" of presentation. Following these findings, Schneider (1992) proposed that differences in aspiration accounted for the lack of consistency between framing arenas.

Further research investigating the framing phenomenon demonstrated that person factors such as need for cognition (Chatterjee, Heath, Milberg \& France, 2000; Smith \& Levin, 1996; Zhang \& Buda, 1999), perceptions of threat (Highhouse \& Yuce, 1996; Highhouse \& Paese, 1996), individual perceptions (Frisch, 1993) and personality traits including intuition (Levin, Gaeth \& Schreiber, 2002) can all effect the likelihood of framing. Similar to person factors, a number of contextual factors have also been shown to affect the potential for framing. Examples include statistical versus medical context (Bless, Betsch \& Franzen 1998), decision time (Takemura, 1992), target of the task (Levin\&Chapman, 1990, Wang, 2001) and presentation format (Fagley \& Miller, 1997). Attesting to much of this inconsistency, Kuhberger (1998) found in a meta-analytic review of framing research that the overall effect for framing was relatively small $(d=0.33)$. The strongest framing effect seemed to be found with scenarios that most closely followed the Asian disease problem (see Appendix 1) and, not surprisingly, some types of framing scenarios seemed to produce no framing effects at all. 


\section{DUAL-PROCESS APPROACH}

In recent decades, researchers investigating various psychological phenomena have developed numerous dual-process models (e.g., Chaiken, 1987; Epstein, Lipson, Holstein\&Huh, 1992; JohnsonLaird \& Byrne, 1993; Petty \& Cacioppo 1986; Stanovich \& West, 2000). The focus of this research has spanned across both social and cognitive psychology. Because of the extensive history of the dual-processing approach, it has been the foundation for a large number of studies that have demonstrated its potency. Consequently, it remains one of the most investigated and important frameworks in social psychology (see Chaiken \& Trope, 1999 for review).

While most dual-process models focus on specific topics and have theoretically identifying characteristics, they nonetheless maintain a central theme. They posit that two distinct processing modes or systems exist. One system requires relatively more effort and performs a more comprehensive analysis of the information. While the other system requires relatively less effort and, consequently, performs a less extensive analysis of the information.

\section{ANALYTIC/HOLISTIC DISTINCTION}

Recently, McElroy and Seta $(2003,2004)$ proposed a dual-process account to explain some of the discrepancies found within the framing literature. According to this view, individuals process decision tasks using both analytic and holistic processing styles. In a typical decision task, either the analytic or holistic processing style can be particularly influential depending upon personality, relevance and hemispheric factors.

Consistent with prior dual-process theories (e.g., Chaiken, 1987; Epstein, Lipson, Holstein \& Huh, 1992; Johnson-Laird \& Byrne, 1993; Petty \& Cacioppo 1986; Stanovich \& West, 2000), the analytic/holistic model proposes two systems of processing that operate under different principles. Although most individuals typically operate under the less effortful-holistic processing style, several factors can either induce or predispose individuals to process a task using the more effortful-analytic processing style. When the task is of sufficiently high relevance, the more effortful, analytic system is induced whereas if the task is of low personal relevance, the less effortful-holistic system is induced. Further, both systems have a personality component that can predispose individuals to one or the other systems of processing.

Demonstrating these points, McElroy and Seta (2003) found that when participants were given the traditional Asian disease problem (see Appendix 1), typical framing effects occurred only when 
the task was presented as being of relatively low personal relevance or when individuals had a personality predisposition favoring holistic thought (McElroy \& Seta, 2003).

The analytic/holistic account differs from prior dual-processing accounts in two fundamental ways. First, the analytic/holistic model suggests that, in addition to effort and personality factors, the functional specializations of the respective hemispheres provide a representative basis for the two system of processing (McElroy \& Seta, 2004). The left hemisphere represents the analytic system whereas the right hemisphere represents the holistic system. The analytic/holistic view differs further from other dual-process models in the functionality of the two systems. The analytic system focuses on breaking information down into distinct and unconnected elements, then combining this information and focusing on quantitative weights for solutions. The holistic system differs from other accounts primarily because of "contextual referencing"the holistic system is especially sensitive to cues within the surrounding context. The contextual cues then act to elicit a framework within which the problem can be evaluated. This process is largely derived from work investigating language comprehension (e.g., Brownell, Pincus, Blum, Rehak, \& Winner, 1997).

According to the dual analytic-holistic approach then, if a person identifies the target of a framing task as an important identifying aspect of their self-construct, then related information should be of especially strong personal relevance. Consequently, individuals should process the task with the more effortful-analytic processing style and the predicted framing effects should not occur. Conversely, if the target of the task is not particularly tied to their self-construct, then personal relevance should be low and the less effortful-holistic style should be selected. This should result in special sensitivity to contextual cues (i.e., the frame) and commonly found framing effects should occur. One way that individuals differ in their self- identifying attachments is in their identity orientation toward groups.

\section{COLLECTIVE IDENTITY}

While we each hold individual aspects of our selves central to our personal self-view, we also have aspects of our self that are related to groups we encounter (family, faculty, swim clubs etc.). Research examining this differentiation (e.g., Brewer \& Gardner, 1996; Cheek 1989; Seta, Seta \& Hundt, 2001) supports the view that this "group" aspect of our self has a unique importance to our self-concept-separate from individual aspects of our self. Consequently, both personal and collective identities can have differential effects on a person's evaluation (Long, Spears \&Manstead, 1998). The construct that reflects the importance of social groups 
to an individual's self-concept is collective identity (Luhtanen \& Crocker 1992).

As with most individual traits, individual levels of collective identity vary from person to person (e.g., Cheek, 1989; Luhtanen \& Crocker 1992). And because collective identity is such an important aspect of an individual's self-concept, it is not surprising that those individuals with high levels of collective identity will be especially prone to group bias (e.g., Rubin \& Hewstone 1998). For example, Crocker and Luhtanen (1990) found that high collective individuals were more likely to enhance their in group after receiving failure. Therefore, both theoretical and empirical findings support the claim that individuals differ in their levels of collective identity. And, because collective identification is the determining factor for level of importance in a group related task, we can make certain overall predictions about the likelihood of framing influences on a group-based risky-choice framing task.

\section{ANALYSIS OF A GROUP-BASED TASK}

Based on the dual analytic-holistic analysis (McElroy \& Seta, 2003), when a decision task is of relatively low importance, individuals should process the task with the less effortful, holistic processing style. Therefore, individuals who have a low level of collective identification should evaluate a task involving their group as being less important and engage the task with amore holistic processing style. As a result, low collective individuals should be especially sensitive to contextual cues (i.e., the frame) and the commonly found framing effects should occur.

Amuch different type of response can be predicted for those individuals who have a high level of identification with groups. Consistent with the analytic-holistic analysis, when the decision task is of relatively high importance, individuals should rely upon the more effortful, analytic processing style. And because high collective individuals perceive group-relevant information as being of greater personal importance, they should process a framing task involving their group with the more effortful-analytic style of processing. Therefore, high collective individuals evaluating a framing task involving their group should not demonstrate the predicted framing effects.

\section{OVERVIEW OF STUDY}

In order to investigate the analytic/holistic predictions for a group based, gain/loss framing task, we measured individuals' own personality predispositions and manipulated the framing of the task. We constructed the task so that individuals were faced 
with a typical risk-no risk choice paradigm involving their own

school. Prior to the presentation of the decision task, each individual's

level of collective importance was determined using a

collective identity scale.

\section{EXPERIMENT 1}

\section{METHOD}

Participants and Design. The participants in this study were 94 female introductory psychology students. All females were used for reasons of homogeneity and because they represented the majority of the subject pool.

We measured each individual's level of group identification by using a collective identity scale (Luhtanen \& Crocker, 1992). Participants were then randomly assigned to either the gain or loss framing condition. This yielded a 2-way factorial design of Collective Importance (high, low) X Frame (gain, loss).

Procedure and Materials. Upon arrival, participants were informed that they would be asked their opinion on several items.

They were then instructed that they should turn each item face down on the desk in front of them after they had completed it.

Participantswere first presented with the Luhtanen and Crocker (1992) collective identity scale. This scale consists of 16 items and is a well validated means for assessing collective identity (Luhtanen $\&$ Crocker, 1992). After they had finished the collective identity scale, participants were presented with the group framing task.

The group framing task was adapted from materials used in prior framing research (Fagley \& Miller 1990). In the initial vignette, participants were told:

Imagine that UNCG has projected that 1000 students will drop out of school during the next year. Two programs have been proposed to address this problem, but only one can be implemented. Based on UNCG's experiences with the programs, estimates of the outcomes that can be expected from each program can be made. Assume for purposes of this decision that these estimates of the outcomes are accurate and are as follows:

Participants were then presented with the risk and no risk choices, framed as either gains or losses (losses condition presented in parentheses). For the no-risk option participants were told that:

If program 1 is adopted, 400 of the 1000 students will stay in (drop out of) school. 
In the risk option, participants were told that:

If program 2 is adopted there is $2 / 5$ chance that all 1000 students will stay in (drop out of) school and 3/5 chance that none of the 1000 will stay in (drop out of) school.

After participants had completed the group framing task they were properly debriefed and dismissed.

\section{RESULTS AND DISCUSSION}

Because our central hypothesis revolves around how personal importance of the decision task can motivate different styles of processing, the importance subscale of the Luhtanen Crocker (1992) collective identity scale has direct theoretical and methodological advantages for our investigation. Therefore, we focused our analysis on the collective importance subscale.1 We also performed a subsequent analysis, exploring individual's responses at differing levels of overall collective esteem. We categorized participants as being either high or low on collective identity importance. This division was based on a median split of collective importance scores. A similar median-split categorization was used to classify participants as high or low on overall collective identity.

To test whether framing effects would be affected by individuals level of collective importance and the target group, we performed a 2 (high/low collective importance) $\times 2$ (gain/loss

framing) nominal logistic chi-square analysis on participant's decisions. The results of our analysis, as may be seen in Table 1, revealed a main effect for framing $X^{2}(1, N=94)=9.46, p<.01$. This effect, however, was qualified by a collective importance $\times$ framing interaction, $X^{2}(1, N=94)=4.47, p<.05$. This interaction suggests that participants' responses depended upon both the gain/loss framing manipulation as well as participants own level of collective identity importance. To test further our hypothesis and access the influence of framing more specifically, we performed a nominal logistic chi-square analysis of participant's decisions within both of the collective identity conditions.

According to our predictions, participants who have a high level of collective importance and evaluate a task involving their group should engage the information with the more effortful-analytic processing style and, as a result, they should be relatively insensitive to the way in which the decision is framed. As expected, a nominal logistic chi-square analysis of participants' decisions in the high collective importance condition did not reveal a framing effect, $X^{2}(1, N=47)=.12, p>.7$. 
TABLE 1. Number of Risk-Avoidant and Risk-Seeking Choices as a Function of Collective Importance, and Framing

\begin{tabular}{|c|c|c|c|c|}
\hline & \multicolumn{4}{|c|}{ Choices } \\
\hline & \multicolumn{2}{|c|}{ Risk-Avoidant } & \multicolumn{2}{|c|}{ Risk-Seeking } \\
\hline & $N$ & $\%$ Total & $N$ & $\%$ Total \\
\hline \multicolumn{5}{|c|}{ High Collective Importance } \\
\hline \multicolumn{5}{|l|}{ Framing } \\
\hline Gains & 16 & 73 & 6 & 27 \\
\hline Losses & 17 & 68 & 8 & 32 \\
\hline \multicolumn{5}{|c|}{ Low Collective Importance } \\
\hline \multicolumn{5}{|c|}{ Framing } \\
\hline Gains & 23 & 88 & 3 & 12 \\
\hline Losses & 9 & 43 & 12 & 57 \\
\hline
\end{tabular}

Further exploration of our hypothesis involves those individuals Who have a relatively low level of importance for groups. According to our hypothesis these individuals should engage the task with the less effortful-holistic processing style and be sensitive to the frame. The analysis of low collective importance participants' decisions did reveal the typical framing effect $X^{2}(1, N=47)=9.46, p<.003$. We concentrated our analysis on the importance subscale of the Luhtanen Crocker collective identity scale because of its direct relevance to our investigation. Although less precise, we also performed an analysis on the overall collective scale. As may be seen in Table 2, this analysis revealed a main effect for framing $x 2(1, N$ $=94)=6.24, p<.01$ and a nonsignificant overall collective identity $\times$ framing interaction $X^{2}(1, N=112)=2.48, p<.12$. However, the pattern of results was similar to those obtained with the collective importance subscale (see Table 2).

TABLE 2. Number of Risk-Avoidant and Risk-Seeking Choices as a Function of General Collective Identity, and Framing

\begin{tabular}{|c|c|c|c|c|}
\hline & \multicolumn{4}{|c|}{ Choices } \\
\hline & \multicolumn{2}{|c|}{ Risk-Avoidant } & \multicolumn{2}{|c|}{ Risk-Seeking } \\
\hline & $N$ & $\%$ Total & $N$ & $\%$ Total \\
\hline \multicolumn{5}{|c|}{ High Collective Importance } \\
\hline \multicolumn{5}{|l|}{ Framing } \\
\hline Gains & 19 & 79 & 5 & 21 \\
\hline Losses & 17 & 71 & 7 & 29 \\
\hline \multicolumn{5}{|c|}{ Low Collective Importance } \\
\hline \multicolumn{5}{|c|}{ Framing } \\
\hline Gains & 20 & 83 & 4 & 17 \\
\hline Losses & 9 & 41 & 13 & 59 \\
\hline
\end{tabular}




\section{SUMMARY}

In this study we found that the individuals' own level of importance for the target of the task systematically affected their choices for risk-seeking or risk-avoiding options. Specifically, the proximal relationship between the target and the persons own identity was the determining factor for the presence or absence of a framing effect. We found that those individuals who had high levels of collective importance demonstrated no framing effects for a framing task involving their group. Conversely, those individuals who had low levels of collective importance did express the typical framing effect for the same group-based task.

\section{GENERAL DISCUSSION}

Research investigating the framing phenomenon has provided mixed results as to its viability across some situational and personal factors. The present study was designed to investigate how processing of a group-based decision task is influenced by group-relevant personal factors (i.e., collective esteem). Our experiment was also designed to test the predictive power of a potential explanatory mechanism, the dual analytic-holistic approach (McElroy \& Seta 2003, 2004).

In this study, we found that for individuals who attached high importance to their collective identification, the framing task was especially important when it involved their in group. As a result of this high level of importance, these individuals processed the in group framing task with the more effortful, analytic processing style and as a result, no framing effects were observed.

Our investigation also yielded interesting results about those individuals who have relatively low collective importance for groups. Because of the low level of importance that these individuals have for groups, they engaged the decision task involving their group with the less effortful, holistic processing style and were especially sensitive to contextual cues found in the frame. As a result, low collective individuals demonstrated the predicted framing effects.

\section{POSSIBLE LIMITATIONS}

In our study we examined how the importance of a group, via collective identity, affected individual responses to a group-based, risky-choice framing problem. The risky-choice framing task that we employed is the foremost studied type of framing task (Kuhberger, 1998). However, there are other methods of framing situations. In fact, Levin, Schneider and Gaeth (1998) differentiate between three unique types of framing. Because, as Levin et al. 
demonstrate, these typologies are unique; our conceptual analysis would have to be adapted to fit situations other than the risk-choice framework.

For example, one type of framing, often utilized in health situations, is what Levin Schneider and Gaeth (1998) term "goal framing." In an often cited example, Meyerowitz and Chaiken (1987) found that for the task of breast self-examination (presumably a task of high importance),participants who received a negatively-framed message were more likely to have positive attitudes about and actually perform breast self-examination relative to participants who received a positively framed message. Similar findings have also occurred for attitudes Wegener, Petty \& Klein (1994).

Comparing across the two typologies one specific difference is that goal framing does not normally elaborate on alternatives. Consequently, the expected value associated with the message cannot be determined (Rothman \& Salovey, 1997). In contrast to the risky-choice framing where the alternatives are laid out in numeric and probability format for analytic comparison, goal framing alternatives have no objective information that can be analytically processed. Consequently, numeric comparison of the alternatives is not possible.

Another limitation could involve group membership. Specifically, does the importance of a group-based task only occur when an individual is a member of the targeted group? In our study participants were all members of the targeted group they were evaluating so we cannot say if this translates to groups in general. However, research by Seta et al. (2001) demonstrates that high collective individuals have a perceptual bias toward groups that extends to groups they do not belong to or have affiliation with. This research suggests that high collective individuals may show similar results for framing tasks involving groups that they have no affiliation with. However, it seems likely that increased effortful evaluation is more likely when high collective individuals own in group is involved.

\section{PRACTICAL IMPLICATIONS}

An important implication that emerges from our study is that personality differences can differentially affect a group-based decision.

For example, consider a hypothetical individual who has the task of deciding between potential projects or initiatives that have different degrees of potential risk for their local community. According to our findings, the personality predispositions of the individual may have very real influences on the decision choices they make. In accordance with our findings, we would predict that if our hypothetical individual has a low collective importance for groups; she should then be more influenced by peripheral factors, such as how the information 
is presented. In other words, if the two alternative projects

were presented in such a way that focused on the potential losses, we would suggest that she would be more willing to choose a risky project. Conversely, this individual should be more likely to choose the risk free project if the two alternatives were presented by potential gains that could be accomplished.

Alternatively, different predictions can be made for an individual who has a high level of collective-esteem importance. According to our findings, if our high collective hypothetical individual is presented with a similar situation then, she should be relatively less influenced by how the options are being presented (positively or negatively) and more influenced by analytically derived elements of the alternatives. For example, weighting the potential value of each potential outcome by its probability of occurrence (e.g., Program $X$ with expected value of 17,000 and Program $Y$ with expected value of $20,004)$ and make her decision based upon this analysis.

It would seem from our analysis then, that under the above circumstances, optimal decisions for group-based choices should include both individuals who have a high level of collective importance as well as those individuals who have a low level of collective importance for the group. This should make available both holistically based (i.e., contextual information) as well as more analytically based information for the group decision task.

\section{NOTE}

1. Luhtanen \& Crocker (1992) have validated the use of specific subscales for more specific measurements of the scales components.

\section{APPENDIX 1. ASIAN DISEASE PROBLEM}

\begin{tabular}{|c|c|c|}
\hline Problem & Gains & Losses \\
\hline $\begin{array}{l}\text { Imagine that the U.S. is } \\
\text { preparing for the out- } \\
\text { break of an unusual }\end{array}$ & $\begin{array}{l}\text { If Program } A \text { is adopted, } \\
200 \text { people will be } \\
\text { saved. }\end{array}$ & $\begin{array}{l}\text { If Program } A \text { is adopted, } \\
400 \text { people will die. }\end{array}$ \\
\hline $\begin{array}{l}\text { Asian disease, which is } \\
\text { expected to kill } 600 \text { peo- } \\
\text { ple. Two alternative } \\
\text { programs to combat the } \\
\text { disease have been pro- } \\
\text { posed. Assume that the } \\
\text { exact scientific esti- } \\
\text { mates of the conse- } \\
\text { quences of the programs } \\
\text { are as follows: }\end{array}$ & $\begin{array}{l}\text { If Program B is adopted, } \\
\text { there is a one-third } \\
\text { probability that } 600 \\
\text { people will be saved } \\
\text { and a two-thirds proba- } \\
\text { bility that no people will } \\
\text { be saved. }\end{array}$ & $\begin{array}{l}\text { If Program } B \text { is adopted, } \\
\text { there is a one-third } \\
\text { probability that nobody } \\
\text { will die and a } \\
\text { two-thirds probability } \\
\text { that } 600 \text { people will die. }\end{array}$ \\
\hline
\end{tabular}




\section{REFERENCES}

Bless, H. Betsch, T.,\& Franzen, A. (1998). Framing the framing effect: The impact of contextual cues on solutions to the "Asian disease" problem. European Journal of Social Psychology, 28, 287-291.

Brewer, M. B.,\& Gardner, W. (1996).Who is this "We"? Levels of collective identity and self representations. Journal of Personality and Social Psychology, 71, 83-93.

Brownell, H.H., Pincus, D., Blum, A., Rehak, A., \& Winner, E. (1997). The effects of right-hemisphere brain damage on patients' use of terms of personal reference. Brain and Language, 57, 60-79.

Chaiken, S. (1987). The heuristic model of persuasion. In M.P. Zanna, J.M. Olson, \& C.P. Herman (Eds.), Social influence: The Ontario Symposium (vol. 5, pp.

3-39). Hillsdale, NJ: Erlbaum.

Chaiken, S., \& Trope, Y. (1999). Dual-process theories in social psychology. New York: Guilford Press.

Chatterjee, S., Heath, T.B., Milberg, S.J., \& France, K. R. (2000). The differential processing of price in gains and losses: The effects of frame and need for cognition. Journal of Behavioral Decision Making, 13, 61-75.

Cheek, J.M. (1989). Identity orientations and self-interpretation. In D.M. Buss \& N. Cantor (Eds.). Personality Psychology: Recent Trends and Emerging Directions (pp. 275-285). New York: Springer-Verlag.

Crocker, J.,\&Luhtanen, R. (1990). Collective self-esteem and ingroup bias. Journal of Personality and Social Psychology, 58, 60-67.

Crocker, J., Luhtanen, R., Blaine, B.,\& Broadnax, S. (1994). Collective self-esteem and psychological well-being among White, Black and Asian college students. Personality and Social Psychology Bulletin, 20, 503-513.

Epstein, S., Lipson, A., Holstein, C.,\& Huh, E. (1992). Irrational reactions to negative outcomes: Evidence for two conceptual systems. Journal of Personality and Social Psychology, 38, 889-906.

Fagley, N.S., \& Miller, P.M. (1990). The effect of framing on choice: interactions with risk-taking propensity, cognitive style, and sex. Personality and Social Psychology Bulletin, 16, 496-510.

Fagley, N.S., \& Miller, P.M. (1997). Framing effects and arenas of choice: Your money or your life? Organizational Behavior and Human Decision Processes, $71,355-373$.

Frisch, D. (1993). Reasons for framing effects. Organizational behavior and human decision processes, 54, 399-429. 
Highhouse, S., \& Paese, P.W. (1996). Problem domain and prospect frame: Choice under opportunity versus threat. Personality and Social Psychology Bulletin, 22, 124-132.

Highhouse, S., \& Yuce, P. (1996). Perspectives, perceptions, and risk-taking behavior. Organizational Behavior and Human Decision Processes, 65, 159-167.

Johnson-Laird, P.N., \& Byrne, R.M.J. (1993). Models and deductive rationality. In K. Manktelow \& D. Over (Eds.) Rationality: Psychological and Philosophical Perspectives. Florence, KY: Routledge Press.

Kahneman,D.,\&Tversky, A. (1979). Prospect theory: Ananalysis of decision under risk. Econometrica, 47, 263-291.

Kuhberger, A. (1998). The influence of framing on risky decisions: A meta-analysis. Organizational Behavior and Human Decision Processes, 57, 23-55.

Levin, I..P., Schneider, S.L., Gaeth, G.J. (1998). All frames are not created equal:A typology and critical analysis of framing effects. Organizational Behavior\& Human Decision Processes, 76, 149-188.

Long, K.M.. Spears, R.,\& Manstead, A.S.R. (1994). The influence of personal and colective self-esteem on strategies of social differentiation. British Journal of Social Psychology, 33, 313-329.

Luhtanen, R., Crocker, J. (1992).A collective self-esteem scale: Self-evaluation of one's social identity. Personality and Social Psychology Bulletin, 18, 302-318.

McElroy, T.,\& Seta, J. J. (2003). Framing effects: Ananalytic-holistic perspective. Journal of Experimental Social Psychology, 39, 610-617.

McElroy, T.,\& Seta, J. J. (2004). On the other hand aml rational? Hemispheric activation and the framing effect. Brain and Cognition, 55, 572-580.

Meyerowitz, B. E., \& Chaiken, S. (1987). The effect of message framing on breast self-examination attitudes, intentions and behavior. Journal of Personality and Social Psychology, 52, 500-510.

Petty, R.E., Cacioppo, J.T. (1986). Communication and Persuasion: Central and Peripheral Routes to Attitude Change. New York: Springer-Verlag.

Rothman, A. J.,\& Salovey, P. (1997). Shaping perceptions to motivate healthy behavior: The role of message framing. Psychological Bulletin, 121, 3-19.

Rubin, M.,\& Hewstone, M. (1998). Social identity theory's self-esteem hypothesis: A review and some suggestions for clarification. Personality and Social Psychology Review, 2, 40-62.

Schneider, S. L. (1992). Framing and conflict: Aspiration level contingency, the status quo, and current theories of risky choice. Journal of Experimental Psychology: Learning, Memory, and Cognition, 18, 1040-1057. 
Seta, J.J., Seta, C.E.,\& Hundt, G.M. (2001). Exaggerating the differences between relatively successful and unsuccessful groups: Identity orientation as a perceptual lens. Group Dynamics, 5, 19-32.

Smith, S. M., \& Levin, I.P. (1996). Need for cognition and choice in framing effects. Journal of Behavioral Decision Making, 9, 283-290.

Stanovich, K.E., \& West, R.F. (2000). Individual differences in reasoning: Implications for the rationality debate? Behavioral and Brain Sciences, 23, 645-726.

Tajfel, H. (1982). Social psychology of intergroup relations. Annual Review of Psychology, 33, 1-39.

Takemura, K. (1992). Effect of decision time on framing of decision: A case of risky choice behavior. Psychologia, 35, 180-185.

Triandis, H.G. (1989). The self and social behavior in differing cultural contexts.

Psychological Review, 96, 506-520.

Wegener, D. T., Petty, R. E.,\& Klein, D. J. (1994). Effects of mood on high elaboration attitude change: The mediating role of likelihood judgments. European

Journal of Social Psychology, 24, 25-43.

Zhang, Y., \& Buda, R. (1999). Moderating effects of need for cognition on responses to positively versus negatively framed advertising messages.

Journal of Advertising, 28, 1-15. 